\title{
EDUCAÇÃO PARA AS RELAÇÕES ÉTNICO-RACIAIS NO \\ MUNICÍPIO DA SERRA-ES: UMA ANÁLISE DAS \\ ORIENTAÇÕES CURRICULARES DE 2008
}

\section{EDUCATION OF ETHNIC-RACIAL RELATIONS IN THE MUNICIPALITY OF SERRA-ES: AN ANALYSIS OF THE CURRICULAR GUIDELINES OF 2008}

\author{
Franciele Teixeira da Silva Polez \\ Instituto Federal do Espírito Santo - IFES \\ Joelma dos Santos Rocha Trancoso \\ Instituto Federal do Espírito Santo - IFES \\ Eduardo Augusto Moscon Oliveira \\ Universidade Federal do Espírito Santo - UFES
}

\begin{abstract}
RESUMO:
Este trabalho analisa as Orientações Curriculares para a Educação Infantil e anos iniciais do Ensino Fundamental do município de Serra - ES, a fim de investigar se o documento em vigência contempla a lei federal $n^{0}$ 10.639/2003 e ações para a Educação para as Relações Étnico-Raciais (ERER) no currículo escolar da rede municipal de ensino. Tendo em vista a luta do Movimento Negro, o currículo como espaço de poder e os debates atuais sobre a negritude, compreendemos a importância desta reflexão para a valorização da diversidade étnico-racial e combate ao racismo no ambiente escolar. O trabalho utilizou-se de uma pesquisa qualitativa, com o emprego da técnica de pesquisa documental (Gil, 2010) sobre as Orientações Curriculares (OC) de Serra-ES, construídas em 2008 e ainda vigentes. Com os resultados da análise, consideraremos a necessidade de revisão do documento orientador, para que o trabalho da questão étnico-racial na Educação Infantil e nos anos iniciais do Ensino Fundamental seja efetivado.
\end{abstract}

Palavras-chave: Orientações Curriculares. Lei $n^{0}$ 10.639/2003. Educação das Relações Étnicoraciais. Educação Infantil. Anos Iniciais.

\section{ABSTRACT:}

This paper analyzes the Curricular Guidelines for Early Childhood Education and early years of Elementary Education in the municipality of Serra - ES, in order to investigate whether the current 
document contemplates federal law No. 10.639 / 2003 and actions for Education for Ethnic- (ERER) in the school curriculum of the municipal school system. Bearing in mind the struggle of the Black Movement, the curriculum as a space of power and the current debates about blackness, we understand the importance of this reflection for the valorization of ethnic-racial diversity and the fight against racism in the school environment. The work used a qualitative research, with the use of the documentary research technique (Gil, 2010) on the Curricular Guidelines (OC) of Serra-ES, built in 2008 and still in force. With the results of the analysis, we will consider the need for revision of the guiding document, so that the work of the ethnic-racial issue in Early Childhood Education and in the early years of Elementary School is carried out.

Keywords: Curricular Guidelines. Law no 10.639 / 2003. Education of Ethnic-racial Relations. Early Childhood Education. Early Years 


\section{INTRODUÇÃO}

"Tava durumindo
cangoma me chamou
Disse levanta povo
cativeiro já acabou."1

Em 1982, a cantora negra carioca, Clementina de Jesus da Silva, entoava um vissungo ${ }^{2}$ em ritmo de jongo intitulado "Cangoma Me Chamou". A palavra "Cangoma”, na língua bantu significa tambor, mas também faz referência a ocasião em que os negros escravizados se reuniam para dançar, cantar e tocar na festa dos tambores. A música de Clementina de Jesus, escrita nas últimas décadas do século XX, é uma inquietação e um chamado para a luta do direito à liberdade e cidadania, legalmente inviabilizadas no Brasil por 353 anos, e que, ainda hoje, não fora plenamente conquistada por muitos negros afro-brasileiros.

$\mathrm{O}$ século XX foi marcado pelos movimentos negros que, como tambores, ecoaram o grito pela liberdade, despertando nos espaços políticos o diálogo e a discussão das questões inerentes à negritude. Como exemplo desses movimentos, temos o Centro Cívico de Palmares (1926), a Frente Negra Brasileira (1931) e o Teatro Experimental do Negro (1944). Em 1971, com a criação do Grupo Palmares, contestouse a legitimidade do signo imputado a "abolição" na data de 13 de maio, confrontando com o 20 de novembro, que mais tarde tornou-se o "Dia Nacional da Consciência Negra”. Em 1972, nasce o Centro de Cultura e Arte Negra (Cecan) e em 1978 estabelecese o Movimento Negro Unificado (FORDE, 2018).

Para Forde (2018), os anos 1970 foram cruciais para um novo olhar sobre a questão racial no Brasil. Os movimentos enfatizavam a importância da valorização da história, cultura e identidade negra, e ratificaram a Educação como principal estratégia para esta tarefa.

\footnotetext{
${ }^{1}$ Clementina de Jesus (Canto dos Escravos: Discografia de 1982)

${ }^{2}$ Vissungo, em etnografia, se refere a música de caráter responsorial praticada por escravos africanos utilizados não só nas lavras de diamantes e ouro na região compreendida, entre outras, pelas periferias das cidades brasileiras de Diamantina, São João da Chapada e Serro, no estado de Minas Gerais. (https://pt.wikipedia.org/wiki/Vissungo)
} 
Fortalecido, o Movimento Negro Unificado (MNU) ampliou-se pelo Brasil na década de 1980 e colocou a questão racial como pauta em grande parte do país. Por isso, em 1982, Clementina de Jesus entoava o chamado da cangoma para o resgate da ancestralidade africana.

Sobre a expansão do Movimento Negro Unificado no Brasil, estudos de Forde, Poltronieri e Venerano (2004) apontam que o estado do Espírito Santo foi um dos pioneiros a legislar sobre a obrigatoriedade do ensino da temática afro-brasileira nas redes de ensino. O MNU compreendia a escola, enquanto espaço de socialização e racialização do outro, “[...] como importante ferramenta de desconstrução do imaginário erguido por interlocutores eurocentristas [...]” (TRANCOSO, 2019, p.32).

Para Trancoso (2019), o município de Serra/ES, em função de ações de resistência e luta do movimento negro, promulgou a Lei $\mathrm{n}^{\mathrm{o}} 2387$, de 30 de maio de 2001, normatizando no Art. $2^{\circ}$ a inclusão "[...] no Currículo escolar as informações sobre a História e Cultura das Populações Negras, Indígenas e o folclore do povo serrano e capixaba;" (SERRA, 2001, p. 1).

Na esteira dessas históricas formas de resistência, destacamos a importância da III Conferência Mundial de Combate ao Racismo, Discriminação Racial, Xenofobia e Intolerância Correlata, em Durban, África do Sul, realizada em 2001, cujas declarações e documentos tornaram-se referência internacional.

Naquele ano, todas formas de luta relativas à educação manifestadas pelos Movimentos Negros com destaque aos esforços do Movimento Negro Unificado, culminaram na Conferência de Durban. Como consequência, pela primeira vez o Brasil assumia publicamente o compromisso de desenvolver ações afirmativas contra o racismo e a discriminação racial também no âmbito da Educação.

Compreendemos assim como Almeida e Sanchez (2017) que leis são consequência de processos de embates e disputas da sociedade em torno de múltiplos interesses. Sendo assim, a concepção e inclusão de uma lei que obriga o ensino sobre História e Cultura Afro-Brasileira nos estabelecimentos de ensino fundamental e médio, oficiais e particulares de todo país é fruto de tensões históricas que visam reconhecimento e reparação das desigualdades entre populações negras e não negras do Brasil. 
A promulgação das Leis 10.639/2003 e 11.645/2008, que alteraram a LDB no 9.394/1996, está inserida no conjunto das políticas afirmativas para a promoção da equidade racial nas práticas pedagógicas da educação básica. De acordo com Gomes (2001):

Os objetivos das ações afirmativas são: induzir transformações de ordem cultural, pedagógica e psicológica, visando a tirar do imaginário coletivo a idéia de supremacia racial versus subordinação racial e/ou de gênero; coibir a discriminação do presente; eliminar os efeitos persistentes (psicológicos, culturais e comportamentais) da discriminação do passado, que tendem a se perpetuar e que se revelam na discriminação estrutural; implantar a diversidade e ampliar a representatividade dos grupos minoritários nos diversos setores; criar as chamadas personalidades emblemáticas, para servirem de exemplo às gerações mais jovens e mostrar a elas que podem investir em educação, porque teriam espaço (GOMES, 2001, p. 6-7).

Petit reforça:

[...] no campo dos avanços voltados para a população negra, a Lei $n^{\circ} 10.639 / 03$ foi um marco histórico de suma importância como política de reparação, valorização e afirmação, promovendo transformações muito significativas [...] (PETIT, 2016, p.661).

As leis 10.639/2003 e 11.645/2008 vieram, com muita luta, para quebrar paradigmas por meio da dinâmica da educação. No entanto, dezessete anos depois, ainda encontramos currículos vagos de africanidades privilegiando e valorizando a branquitude. Concordamos com Aplle (1994) que currículo não é um elemento neutro, ele está relacionado ao poder. É consequência de uma “tradição seletiva” resultado da seleção de alguém, da visão de determinado grupo acerca do que seja conhecimento legítimo.

O fato de ainda questionarmos a efetiva inserção da lei 10.639/2003 e 11.645/2008 nos currículos escolares, nos dá indicativos que a "tradição seletiva" dos sistemas escolares ignora e subalterniza propostas de construção da igualdade racial na sociedade brasileira. Os tambores que remetiam a ancestralidade do povo africano, como proclamado por Clementina de Jesus, já tocam a bastante tempo. Mas a pergunta é, será que todos podem ouvir? Será que todos tem acesso aos seus sons?

Cientes de que o município da Serra foi precursor em legislar o ensino da história e cultura africana e indígena, realizamos uma pesquisa qualitativa, com o 
emprego da técnica de pesquisa documental (Gil, 2010), sobre as Orientações Curriculares (OC) do município, construídas em 2008 e ainda vigentes.

O documento intitulado “Orientação Curricular de Educação Infantil e Ensino Fundamental: articulando saberes, tecendo diálogos”, será o principal instrumento de investigação para compreendermos a abordagem da lei $n^{0} 10.639 / 2003$ na rede municipal de ensino. A partir da análise documental, consideraremos a necessidade de revisão para direcionar o trabalho da questão étnico-racial na Educação Infantil e anos iniciais do Ensino Fundamental do município da Serra.

\section{CURRÍCULO E IDENTIDADE NO MUNICÍPIO DA SERRA}

O documento foi construído democraticamente no ano de 2008 e concebe o currículo escolar como um documento de identidade que produz seus próprios significados, permeado por relações de poder (SERRA,2008).

Ao considerarmos o "currículo como documento de identidade, trajetória, território e autobiografia" (SERRA, 2008, p.13), conhecer o perfil dos estudantes, bem como o contexto no qual ele está inserido, torna-se fundamental para efetivarmos um processo educativo que “[...] procura romper com uma concepção de escola única, homogênea, contendo os mesmos sentidos e objetivos para todos” (SERRA, 2008, p. 14).

Assim, apresentamos na tabela 1 (Matrículas por Modalidade e Cor/Raça da Rede Municipal de Serra do Espírito Santo - 2019), o número de matrículas dos estudantes de Educação Infantil e Ensino Fundamental, a fim de identificarmos o perfil étnico-racial da população estudantil da rede municipal de ensino da Serra:

Tabela 1: Matrículas por Modalidade e Cor/Raça da Rede Municipal de Serra do Espírito Santo - 2019

\begin{tabular}{|c|c|c|c|c|c|c|c|}
\hline \multirow{2}{*}{ Modalidade } & \multicolumn{6}{|c|}{ Cor/Raça } & \multirow{2}{*}{ Total Geral } \\
\hline & Branco & Preto & Pardo & Amarelo & Indígena & Não declarada & \\
\hline Educação Infantil & 4.574 & 1.150 & 13.201 & 96 & 25 & 1.894 & 20.940 \\
\hline Ensino Fundamental & 8.520 & 2.204 & 27.533 & 129 & 56 & 3.235 & 41.677 \\
\hline EJA & 221 & 150 & 1.303 & 13 & 4 & 482 & 2.173 \\
\hline Total Geral & $13 \cdot 315$ & 3.504 & 42.037 & 238 & 85 & 5.611 & 64.790 \\
\hline
\end{tabular}

Fonte: Censo Escolar 2019 - Secretaria de Educação do Município da Serra 
Antes de analisarmos os número apresentados, cabe elucidar que o Estatuto da Igualdade Racial, instituído pela lei $\mathrm{n}^{\mathrm{o}} 12.288$ em 20 de julho de 2010, considera como população negra, em parágrafo único - IV: o conjunto de pessoas que se autodeclaram pretas e pardas, conforme o Instituto Brasileiro de Geografia e Estatística (IBGE). Assim, podemos afirmar, com base nos dados estatísticos do Censo Escolar 2019, que 69,5\% da população estudantil do município serrano é negra.

Em face deste número expressivo, para conceber currículo como documento de identidade, a Educação para as Relações Étnico-Raciais e a lei no 10.639/2003 são necessárias para a valorização e promoção da diversidade e do pertencimento étnicoracial. Em vista disso, realizamos uma análise documental da Orientação Curricular (OC 2008) que ainda está em vigência, para identificarmos a presença da ERER e da referida lei na Educação Infantil e nos anos iniciais do Ensino Fundamental.

\section{UMA ANÁLISE DA OC DE 2008}

No texto introdutório, o documento orientador afirma que "[...] foram propostos alguns enunciados que deveriam ser considerados no processo de reflexão e escrita do documento[...]" (2008, p. 14). Um destes enunciados, trata-se do "Fortalecimento da dinâmica ensino-aprendizagem, potencializando diferentes formas de inclusão, garantias de acesso ao conhecimento e permanência na escola” (SERRA, 2008, p. 16). Neste enunciado, a OC de 2008 descreve, resumidamente, sobre as diferenças:

\footnotetext{
As diferenças, ao invés de ser compreendidas como um campo de desigualdades, devem constituir-se como uma possibilidade inesgotável de trocas culturais. Essa premissa coloca em xeque o quanto o processo ensino-aprendizagem precisa humanizar-se, inserindo diferentes sujeitos em processos educativos que não eliminem a existência das diferenças, mas com elas aprenda a con-viver e a vislumbrar caminhos igualitários de afirmação de direitos. (SERRA, 2008, p. 16)
}

A discussão menciona a existência de processos de exclusão e discriminação de crianças e adolescentes, como consequência de um padrão imposto pela sociedade que legitima privilégios e estabelece estereótipos. Entretanto, a OC não especifica este 
padrão e não constrói uma crítica-reflexiva sobre o privilégio direcionando o debate sobre inclusão e diferença para a modalidade de Educação Especial.

No texto da OC de 2008, o item 3.3 discute premissas para as ações educativas na Educação infantil e anos iniciais do Ensino Fundamental. Efetuamos um recorte dos subitens 3.3.6 Currículo e Diversidade e 3.3.8 O Campo Educativo e as Áreas de Conhecimento, para compor nossa análise.

Em Currículo e Diversidade, o documento desenvolve uma crítica ao conhecimento científico rígido, acrítico, fragmentado e desconectado da realidade, para desconstruir a ideia de um único saber,

“[...]no sentido de promover uma educação que acolha a multiplicidade de saberes, valores e fazeres de seus alunos, que construa novas práticas educativas capazes de efetivar uma aprendizagem contextualizada e significativa" (SERRA, 2008. p. 51).

A OC enfatiza o perigo de uma história única e a necessidade de desmitificar a concepção de Ciência como uma atividade neutra. É preciso encará-la como uma atividade humana carregada de ideologias e interesses (SERRA, 2008).

Apesar de não discutir as raízes branco-ocidentais no currículo escolar brasileiro, o documento destaca que é preciso abordar outras matrizes de saberes para fortalecimento da diversidade cultural:

\begin{abstract}
[...] ]evidencia-se a necessidade de reconhecimento das diferentes matrizes culturais, locais e regionais da realidade sócio-histórica, cultural e econômica dos educandos, o que pode enriquecer o trabalho pedagógico, com implicações na seleção de conteúdos e na elaboração de materiais didáticos de acordo com a realidade em que a escola está inserida. Esse reconhecimento também oferece subsídios à contextualização das disciplinas, reafirmando as matrizes culturais desse lugar e sua história (SERRA, 2008, p. 51).
\end{abstract}

Elencamos na tabela 2 (Procedimentos teórico-metodológicos para o trabalho a partir das diferenças culturais), o que a OC de 2008 denomina como "uma série de procedimentos teórico-metodológicos necessários para organizar o trabalho da escola a partir das diferenças culturais” (SERRA, 2008, p. 52): 
Tabela 2: Procedimentos teórico-metodológicos para o trabalho a partir das diferenças culturais

1. Criar um ambiente agradável, respeitoso e acolhedor dessas diferenças, rompendo com preconceitos, atitudes cristalizadas e currículos fechados;

2. Superar o conhecimento único e absoluto, por meio da valorização dos diferentes saberes e fazeres, assumindo-o como uma forma de produção cultural, no sentido de tomar a cultura e o conhecimento como formas de produção e manifestação da vida, e a implicação disso para as unidades de ensino é que, enquanto instituição, ela deve estar aberta às diferentes formas de produção cultural, às diferentes formas de conhecimento reveladas nessa produção;

3. Garantir planejamento coletivo entre profissionais da escola, permitindo a troca de experiências, com vistas a desenvolver um trabalho vinculado à valorização do espaço tempo de cada educando;

4. Reafirmar a escola a serviço dos educandos, por meio de um trabalho contextualizado, transdisciplinar, que valorize as potencialidades e as diferenças culturais da Serra.

Fonte: Orientação Curricular de Educação Infantil e Ensino Fundamental: articulando saberes, tecendo diálogos (2008).

Refletindo sobre os procedimentos apresentados, identificamos que o ensino da diversidade na OC de Serra, apresenta-se de forma bem ampla. Reconhecem que há exclusão, discriminação e preconceito, assim como diferenças culturais no município, porém as orientações não tecem uma reflexão-crítica sobre um currículo que legitima o privilégio branco. Este silêncio, fortalece práticas racistas e aliena práticas pedagógicas, impedindo a conscientização e promoção da diversidade étnico-racial no ambiente escolar (MUNANGA, 2008).

Considerando que as orientações curriculares devem assegurar a autonomia e a especificidade dos sujeitos da escola, compreende-se ser indispensável uma orientação curricular que demande práticas pedagógicas que "visem o reconhecimento da diversidade da diversidade étnico-racial e o tratamento digno da questão racial e do povo negro no cotidiano escolar" (GOMES, 2018, p. 49).

O subitem O Campo Educativo e as Áreas de Conhecimento, aponta para a relevância da interdisciplinaridade no currículo escolar e a necessidade de relacionar os conteúdos ao cotidiano do aluno, para que sejam capazes de realizar uma leitura de mundo e atuar sobre ele.

Contudo, os objetivos e orientações para o desenvolvimento das áreas de conhecimento, não mencionam o ensino da história e cultura africana, afro-brasileira e indígena, tampouco tecem reflexões sobre o racismo: "cristalizado na estrutura de nossa sociedade" (GOMES, 2018, p. 51).

Para Forde, Poltronieri e Venerano (2004, p.9), o currículo prescrito e o currículo real são um espaço de poder. Incluir questões étnico-raciais nas diretrizes 
curriculares das redes de ensino, passam por uma questão de implementação de políticas de ação afirmativa e justiça social. Assim, o fato dessa questão não ser abordada em nenhum dos objetivos das áreas de conhecimento, nos dá indícios de negação dessas políticas.

No entanto, entendendo a importância de um olhar mais aprofundado, com intuito de evitar um juízo de valor precipitado, compreendemos a necessidade de se fazer uma análise das concepções e orientações metodológicas para cada disciplina, a fim de investigarmos se a temática tem sido contemplada.

\subsection{A ERER NAS ÁREAS DE CONHECIMENTO DA OC DE SERRA}

Inicialmente, cabe destacar que a OC do município da Serra faz uma importante ressalva sobre a necessidade de se pensar a inter-relação entre as áreas de conhecimento, afirmando como base, a necessidade do diálogo entre os campos de saberes.

[...] de uma forma geral, as disciplinas, apesar de se apresentarem compartimentadas no currículo, permeiam em conjunto a questão da aprendizagem, da consciência corporal e das múltiplas alfabetizações (matemática, linguística, científica, artística, em seus diferentes matizes...). Assim, na organização do trabalho pedagógico, devese considerar, na realidade cotidiana dos educandos, a interrelação entre os diferentes conhecimentos para favorecer os processos de aprendizagem (SERRA, 2008, p. 56).

Apesar deste apontamento, por questão de produção e organização do documento orientador, as áreas de conhecimento são expostas de forma separada. Nesse sentido, iremos arrolar e analisar as áreas de conhecimento tal qual como apresentadas pelas OC (2008).

\subsubsection{ARTE}

A disciplina de Arte nos toma de forma provocativa ao começar indagando as relações de poder do currículo. Ao questionar o que se pode esquecer e o que é necessário lembrar, promove uma reflexão sobre a própria prática. 


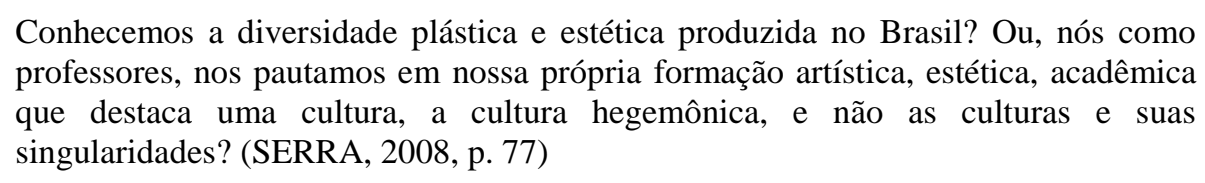

A referida disciplina, não cita em nenhum momento a lei $\mathrm{n}^{\circ}$ 10.639/o3 ou dá qualquer indício da lei $\mathrm{n}^{\mathrm{o}}$ 11.645/2008, promulgada em março de 2008. No entanto, apresenta em linhas gerais um rompimento com o paradigma que enaltece um único ponto de vista, estabelecendo que a disciplina de Arte deve partir do lugar onde se está no mundo, considerando e valorizando o contexto cultural do aluno "[...] construindo ao longo da vida escolar um diálogo entre o que já foi aprendido, não esquecendo a produção local, principalmente as manifestações populares” (SERRA, 2008, p. 85).

\subsubsection{CIÊNCIAS NATURAIS}

Nas Ciências Naturais, o texto introdutório contextualiza o perfil socioambiental do município da Serra a partir da exploração de colonizadores europeus. Essa concepção histórica, em nossa análise, confere invisibilidade aos povos originários e possibilita ao leitor uma compreensão de que o município foi descoberto e desenvolvido pelo homem branco europeu. Quando na verdade, pesquisas confirmam que o território serrano já era habitado pelos indígenas tupiniquins muito antes da chegada dos portugueses ao Brasil, em 1500.

As orientações para Ciências, indicam que o estudante deve ser o sujeito de sua aprendizagem. Elas tecem uma crítica ao livros didáticos que uniformizam temas, alegando que não prestigiam especificidades e a diversidade cultural. Sugerem a construção de projetos interdisciplinares com base nas situações cotidianas, a fim de que haja reflexões e ações pedagógicas sobre elas. No entanto, as questões étnicoraciais são minimamente discutidas.

Pesquisas evidenciam ser a escola o local onde as crianças negras têm suas primeiras experiências com o racismo. Experiências estas "que marcam significativamente sua escolarização ou mesmo sua saída do sistema educacional” (SILVA, 2009, p. 11). Diante disso, promover projetos interdisciplinares que envolvem 
a educação para as relações étnico-raciais na Educação Infantil e anos iniciais do Ensino Fundamental é uma demanda vivaz.

Outro ponto chave da disciplina de Ciências são as práticas pedagógicas realizadas nos espaços de educação não-formal. As OC indicam aulas campo, o que representa uma oportunidade para explorar o rico e extenso patrimônio histórico cultural africano, afro-brasileiro e indígena que existe no território serrano, possibilitando aprendizagens que valorizem e fortaleçam a diversidade e pertencimento étnico-racial.

\subsubsection{EDUCAÇÃO FÍSICA}

No que tange a disciplina da Educação Física, a OC nos situa historicamente sobre a sua concepção enquanto conhecimento, que por vezes foi contemplada somente no campo do esporte ou da saúde ou da psicomotricidade.

A partir da perspectiva histórica descrita no documento, os professores indicam caminhos de práticas plurais numa visão progressista, onde o corpo não é dissociado da mente. Nesse sentido, a rede de Serra entende a Educação Física como disciplina que é "[...] pensada sob a perspectiva da cultura corporal de movimento e trata didático-pedagogicamente das diferentes formas culturais do movimentar-se humano" (SERRA, 2008, p.128). Assim, traz conteúdos referentes aos diferentes temas da cultura corporal de movimento, como o jogo, a dança, a luta, o esporte, a ginástica, as artes circenses e outros.

Na OC para Educação Física a cultura é concebida como norteadora desse campo do saber. O texto ressalta a diversidade geográfica, social e cultural presente no município da Serra, dá indícios de construção de uma prática pedagógica críticoemancipatória e revela, em suas linhas, experiências de professores que tentaram desconstruir estereótipos e preconceitos sobre a história e cultura negra:

Os professores relataram, também, conflitos enfrentados em relação ao desenvolvimento de certas práticas corporais em determinados contextos em que se apresentam questões de cunho religioso que acabam dificultando e, no extremo, até mesmo impedindo a prática pedagógica dos professores no que tange ao ensino de 
certos conteúdos. Isso revela que o dever e o direito de laicidade da escola pública nem sempre são respeitados (SERRA, 2008, p.128).

Apesar das falas dos professores demonstrarem a pressão cotidiana, exercida pelo padrão "homem branco cristão", que atravessa a comunidade e a escola, demonizando tudo que foge desse conceito, a OC da Serra não comenta as questões étnico-raciais, e seu silenciamento corrobora para a propagação dos efeitos nefastos do racismo.

\subsubsection{ENSINO RELIGIOSO}

Até o momento, a OC para o Ensino Religioso é a que mais aborda o racismo, e, dada a sua particularidade, a intolerância religiosa. Ela traz como objetivo do Ensino Religioso, a valorização do pluralismo e da diversidade cultural presente na sociedade serrana e capixaba, buscando contribuir positivamente para o diálogo intercultural entre as pessoas de diversos credos religiosos.

O texto aponta que a função da disciplina é garantir o respeito à liberdade de crença e consciência, incentivando o respeito ao outro e a sua religião, seja ela qual for, dentre elas, as de matrizes indígenas, africanas e orientais (SERRA, 2008, p. 153). O racismo, enquanto construção social, deve ser problematizado e as orientações demandam responsabilidade à escola e família para romperem qualquer modelo de discriminação. Apesar de não abordar as leis $n^{0}$ 10.639/2003 e $n^{0} 11.645 / 2008$, a disciplina de Ensino Religioso demonstra de forma explicita a preocupação com a pluralidade étnico-racial.

\subsubsection{GEOGRAFIA}

No campo da Geografia, a OC apresenta um resumo histórico que tece reflexõescríticas acerca do período pós-guerra mundial, no qual a Geografia e a História fundiram-se em "Estudos Sociais" nas escolas do Brasil. De acordo com as OC de 2008, essa redução tratou-se de uma 
[...] estratégia para a diminuição dos embates políticos, na nova ordem do mundo capitalista. Passou-se a privilegiar a formação tecnicista, para a formação da mão-deobra necessária às demandas geradas pelo crescimento industrial, que afetou tanto o campo quanto as cidades brasileiras. Em outras palavras, naquele momento, o Estadonação precisava mais de uma disciplina que pudesse contribuir para a construção e a preservação da identidade nacional, porém sem dar margens à polêmica (SERRA, 2008, p. 164, grifo nosso).

Essa reflexão, ainda que não discuta a questão étnico-racial, abre caminhos para questionarmos o papel dos Estudos Sociais em alienar práticas pedagógicas e difundir símbolos nacionais que fortaleceram o mito da democracia racial, o privilégio branco e o silenciamento de políticas reparativas à população negra.

Outra contribuição histórica bastante relevante no texto da OC, é o processo de redemocratização do ensino no Brasil, a ação dos movimentos sociais na década de 1970 e a promulgação da Lei das Diretrizes e Bases da Educação Nacional - LDB $\mathrm{n}^{\circ}$ 9.394/1996, que resultaram na volta das disciplinas de História e Geografia no Ensino Fundamental numa perspectiva crítica.

Essas informações, apesar de não estabelecerem uma discussão étnico-racial, possibilitam o debate sobre a importante atuação do Movimento Negro na Educação, pois, foi o Movimento Negro que:

[...] trouxe as discussões sobre racismo, discriminação racial, desigualdade racial, crítica à democracia racial, gênero, juventude, ações afirmativas, igualdade racial, africanidades, saúde da população negra, educação das relações étnico-raciais, intolerância religiosa contra as religiões afro-brasileiras, violência, questões quilombolas e antirracismo para o cerne das discussões teóricas e epistemológicas das Ciências Humanas, Sociais, Jurídicas e da Saúde, indagando, inclusive, as produções das teorias raciais do século XIX disseminadas na teoria e no imaginário social e pedagógico (GOMES, 2018, p. 17).

Na perspectiva da Geografia crítica, defendida na OC de 2008, os efeitos danosos do racismo não são abordados. Porém, podem e devem ser trabalhados para uma reflexão sócio-histórica acerca da desigualdade social brasileira, abarcando a pobreza, os espaços ocupados, a violência, o genocídio negro, entre outras questões étnico-raciais.

Cientes de que esta discussão na Educação Infantil e nos anos iniciais do Ensino Fundamental, não ocorre como no Ensino Fundamental 2, propomos este debate para a formação de professores, que, em sala de aula, podem construir práticas de ensino 
que valorizem a história e cultura negra e indígena, despertando o pensamento crítico dos educandos sobre o mundo que os cerca.

\subsubsection{HISTÓRIA}

Para a disciplina de História, o documento tece um resumo histórico em que utiliza o termo "pós-invasão portuguesa” (SERRA, 2008, p. 188). O item 9.4 Nosso Município, descreve que, na História oficial, os primeiros habitantes de Serra foram os indígenas Tupiniquins e posteriormente os indígenas Temininós, oriundos do Rio de Janeiro. Relata que essas tribos foram escravizadas pelos portugueses e que o fato gerou muitos conflitos, uma vez que os indígenas não aceitavam essa condição.

Além dos indígenas, o texto menciona a escravização de africanos, cuja mão-deobra escrava foi utilizada pelos portugueses para a construção de engenhos. De forma singela, o texto aponta que: "Assim surgiu o povo serrano, que possui características dos colonizadores, dos indígenas e dos afrodescendentes” (SERRA, 2008, p. 188).

Sem tecer críticas-reflexivas ao processo de invasão, colonização e exploração do município, a OC de 2008 apresenta uma linha do tempo resumindo a história local, na qual é possível identificar a presença africana e indígena. Entretanto, a contribuição indígena e africana está diretamente relacionada às revoltas, mão-de-obra escrava e ao folclore.

A OC (2008), também não menciona o ensino obrigatório da história e cultura africana e afro-brasileira, estabelecido pela lei 10.639/2003, tampouco a história e cultura indígena, conforme lei $\mathrm{n}^{0} 11.645$ de 2008. Ela reconhece a diversidade do patrimônio histórico-cultural serrano, porém não valoriza emancipa a herança negra e indígena. É possível observar a escrita tem traços de colonialidade3.

\subsubsection{LÍNGUA INGLESA}

\footnotetext{
${ }^{3}$ Marca ideológica de subalternização do latino-americano e superioridade europeia. (ASSIS, 2017).
} 
A concepção de formação integral permeia toda estrutura da OC de Serra (2008), inclusive a área de conhecimento de Língua Estrangeira. A orientação para a Língua Inglesa destaca que a primeira língua estrangeira falada no Brasil foi a Língua Portuguesa:

[...] ensinada aos nativos de nossa terra e, posteriormente, imposta pelos jesuítas na catequese dos indígenas, o que evidencia os interesses econômicos, políticos e religiosos subjacentes, já nos primórdios da colonização. Seu papel, ora como elemento de colonização/ conscientização, ora como elemento catalisador das relações econômico-culturais, perpassou o ensino das LE através dos tempos, demonstrando serem eles os principais determinantes de sua inclusão nos currículos escolares (SERRA, 2008, p. 2004, grifo nosso).

Diante do exposto, é possível tecer críticas e reflexões acerca do processo de colonização portuguesa e o genocídio da língua nativa, assim como acerca do currículo escolar brasileiro que ainda é regido por uma base branca estrangeira.

Segundo o documento, estudiosos apontam que no Brasil, a língua inglesa é entendida como “[...] culturalmente e cientificamente superior” (SERRA, 2008, p. 207) e que “ [...] é considerada fundamentalmente necessária por constituir-se o meio para o acesso ao mundo e ao conhecimento" (SERRA, 2008, p. 207). Compreendemos que subjetividade, reforça a ideia de supremacia e dominação econômica, política e social, uma vez que, para se comunicar e interagir com o mundo, a língua inglesa torna-se essencial.

Assim, o texto reflete a importância do ensino de língua estrangeira crítico, com base nas concepções de cultura e interculturalidade. E apesar de não discutir diretamente a questão étnico-racial, apresenta reflexões acerca da diversidade: “[...]ao se abrirem para outras culturas, os indivíduos não podem entendê-las como melhores ou piores, mas apenas diferentes" (SERRA, 2008, p. 211). Para isso, o texto afirma que professores e escola precisam abandonar as práticas pedagógicas tradicionais e conceituais, proporcionando aos estudantes uma formação plural e cidadã:

[...] a clientela do Ensino Fundamental encontra-se no momento importante de seu processo de formação ideológica e cultural. Esse momento é caracterizado como o da crítica e das formulações culturais/ideológicas. O papel da escola e do professor de LE, como educador, amplia-se. Assim, além de desenvolver habilidades linguísticas, questões como o fortalecimento e a valorização da identidade nacional, sem que sejam 
fortalecidos estereótipos culturais, deverão ser consideradas. A formação para a cidadania inclui a compreensão do indivíduo sobre sua posição social e as maneiras como pode nela atuar, em busca de mudanças (SERRA, 2008, p. 212).

Em linhas gerais, as orientações curriculares para a Língua Inglesa, foge à maneira tradicional e conteudista, direcionamento as práticas de ensino para uma perspectiva crítica-reflexiva. O texto de 2008 não discute a lei $n^{0} 10639 / 2003$ e relações étnico-raciais, mas abre caminhos para a inclusão.

\title{
2.1.8 LÍNGUA PORTUGUESA
}

[...] o trabalho com a linguagem, seja na educação infantil, seja nos anos iniciais ou nos anos finais do ensino fundamental, deve ser entendido como uma prática social e cultural, intencionalmente organizada, que deve ter como preocupação central a formação de um sujeito crítico, participativo do contexto em que se insere e consciente de suas ações no mundo. (SERRA, 2008, p. 226)

A OC (2008) para a disciplina de Língua Portuguesa também não faz referência à temática étnico-racial, mas, analisando a citação acima, compreendemos que o município orienta o trabalho da linguagem numa perspectiva crítica.

Do ponto de vista teórico-metodológico, as orientações para a Língua Portuguesa afirmam que:

\begin{abstract}
A linguagem é concebida como espaço e lugar de interação verbal. Portanto, de interação entre sujeitos. Dessa forma, entende-se que é pela linguagem que os indivíduos têm acesso a todas as produções humanas, a todo e qualquer tipo de informação. É por meio da linguagem que eles se constituem (SERRA, 2008, p. 231).
\end{abstract}

Se é por meio da linguagem que os sujeitos de constituem, cabe refletir qual linguagem nossos estudantes têm acessado no espaço escolar. Eles são representados? A autoimagem é fortalecida? Que tipos de textos verbais e não verbais são trabalhados na escola? Eles reforçam ou desconstroem estereótipos?

Para Petit (2016), a escrita e linguagem são recursos de dominação. Reforça que foi no século XX que a linguagem e escrita alfabética greco-romana tornou-se preponderante e que essa seria a forma “[...] de negar as mais variadas filosofias milenares existentes no planeta em diversas categorias e classes de gente, como as múltiplas tradições africanas, asiáticas e ameríndias” ( PETIT, 2016, p. 663). 
Assim, compreendemos que um currículo escolar monocultural propaga e reforça o pensamento colonial, o que pode comprometer uma formação para a cidadania plena.

\subsubsection{MATEMÁTICA}

Em sua totalidade, a OC de Serra (2008) tem como base teórica a concepção sócio-histórica, e no campo do saber da Matemática não seria diferente. O documento sinaliza que a escolha metodológica do município se apoia na Resolução de Problemas, e suas diretrizes foram elaboradas considerando a criança e o adolescente como sujeitos históricos e culturais, dando enfoque diversidade presente na sala de aula e os diferentes conhecimentos presentes no contexto escolar (SERRA, 2008, p. 255).

No entanto, como em todo o documento, a palavra diversidade no ensino de Matemática é utilizada de forma bem genérica e não faz referência a questão étnicoracial. Forde (2008) nos alerta, que os conhecimentos matemáticos da história da humanidade são pluriculturais e que não pertence a apenas uma cultura: “ Faz-se necessário substituir o ou de supressão pelo e de inclusão: o legado é simultaneamente, grego, indiano, africano e árabe” (FORDE, 2008, p. 224).

Como alternativas para inclusão desses diferentes saberes, Trancoso (2019), discorre sobre possiblidades educativas com a inspiração na etnomatemática e afroetnomatemática, que visam o resgate e valorização de outras culturas para além das comumente trabalhadas no contexto escolar, como o ensino da Matemática associado à história e cultura africana.

Através da análise documental, observamos que da OC (2008) para o ensino da Matemática é omissa em relação a epistemologia africana e os conhecimentos advindos do povo negro, e não aborda a lei no 10.639/2003.

\section{CONSIDERAÇÕES}

Algarve (2004) afirma que 
Ao chegarem à escola, as crianças negras passam a enfrentar situações de discriminação, devido à cor da sua pele, ao tipo de cabelo, traços físicos, ou as características que não estão de acordo com o modelo de ser humano legitimado pela sociedade, fazendo com que sintam a rejeição da escola à sua pessoa, à cultura do seu povo, e ao grupo étnico-racial à que pertencem (ALGARVE, 2004, p. 12).

A autora pondera que as crianças negras rejeitam suas características físicas por estarem cercadas de referências brancas e por não haver no ambiente escolar materiais que as representem e fortaleçam a sua imagem (ALGARVE, 2014).

Para que ações afirmativas e de pertencimento aconteçam no ambiente escolar, as Orientações e Ações para a Educação das Relações Étnico-Raciais (2006) ressaltam que é preciso fundamentar a prática para uma educação antirracista e que a temática étnico-racial deve ser contemplada no currículo escolar de forma contínua, estabelecendo um diálogo com todas as áreas de conhecimento.

Haja vista que 69,5\% dos alunos matriculados na rede municipal de ensino da Serra-ES, em sua maioria crianças e adolescentes, se autodeclaram negros, e considerando que estes estão em processo de formação e desenvolvimento físico e cognitivo, o trabalho da Educação para as Relações Étnico-Raciais (ERER) na escola torna-se um direito fundamental.

No entanto, a análise documental realizada sobre a Orientação Curricular para a Educação Infantil e Ensino Fundamental do município da Serra (2008), nos mostra que a questão étnico-racial no espaço escolar não é contemplada com a devida relevância. Sabemos que uma orientação curricular é construída coletivamente, onde a comunidade escolar, sobretudo professores, tem participação ativa. Ao mesmo tempo, pesquisas sobre a temática étnico-racial na escola afirmam que muitos professores ainda possuem visões empobrecidas e distorcidas sobre a história e cultura negra, além de valores sociais pautados no preconceito racial, e consideram que temos muito a avançar.

De acordo com a Coordenação de Estudos Étnico-Raciais e Diversidades (CEERD) da Secretaria Municipal de Educação da Serra, desde 2007, o município oferece formação continuada aos profissionais de educação sobre a temática étnicoracial. No entanto, a formação continuada não consegue atingir todo o quantitativo da 
rede e as orientações curriculares tornam-se essenciais para o direcionamento do ensino da diversidade étnico-racial na escola.

A própria OC de 2008 compreende a necessidade de revisitação e crítica ao documento, que precisa estar em constante transformação em diálogo com a realidade mutável. E assimila a importância de "[...] construir um documento como uma narrativa que precisa ser continuada, que necessita ser ressignificada sempre" (SERRA,2008, p. 27).

Tal qual, Munanga (2009, p. 35) acreditamos que "é através da educação que a herança social de um povo é legada às gerações futuras e inscrita na história." Contudo, esta herança precisa ter relação com a ancestralidade. Um currículo monocultural, na perspectiva branco-ocidental, não possibilita o resgate ancestral e condiciona a população negra a um aprendizado colonizador:

\footnotetext{
A memória que lhe inculcam não é de seu povo; a história que lhe ensinam é outra; os ancestrais africanos são substituídos por gauleses e francos de cabelos loiros e azuis; os livros estudados the falam de um mundo totalmente estranho, da neve e do inverno que nunca viu, da história e geografia das metrópoles; o mestre e a escola representam um universo muito diferente daquele que sempre a circundou (MUNANGA, 2009, p. 35)
}

Desde modo, em consonância ao vissungo de Carolina de Jesus, compreendemos que a Orientação Curricular da Serra não assegura o ressoar da educação para as relações étnico-raciais nas escolas da rede. Vislumbramos na açãoreflexão crítica, a possibilidade de reconstrução das orientações para a Educação municipal, para um ato de resistência e efetivação das leis 10.639/2003 e 11.645/2008.

\section{REFERÊNCIAS}

ALGARVE, V. A. Cultura negra na sala de aula: pode um cantinho de Africanidades elevar a autoestima de crianças negras e melhorar o relacionamento de crianças negras e brancas? Dissertação (Mestrado) Universidade Federal de São Carlos, Programa de Pós-Graduação em Educação. São Carlos, 2004. Disponível em: $<$ https://repositorio.ufscar.br/bitstream/handle/ufscar/2661/DissVAA.pdf?sequenc $\underline{\mathrm{e}=1>}$ 
ALMEIDA, M. A. B.; SANCHEZ, L. P. Implementação da Lei 10.639/2003 competências, habilidades e pesquisas para a transformação social. ProPosições vol.28 no.1 Campinas Jan./Apr. 2017. Disponível em < https://www.scielo.br/scielo.php?script=sci arttext\&pid=So10373072017000100055>

APPLE, M.W. "A política do conhecimento oficial: faz sentido a idéia de um currículo nacional?". In MOREIRA, Antonio F. e SILVA, Tomaz T. da. Currículo e cultura e sociedade. São Paulo: Cortez, 1994.

ASSIS, E.V. Liberdade, liberdade! A luta da população negra em queimado perspectivas libertárias para o ensino em relações étnico-raciais. $123 \mathrm{f}$. Dissertação (mestrado) - Instituto Federal do Espírito Santo, Programa de Pósgraduação em Ensino de Humanidades, Vitória, 2017. Disponível em: <https://repositorio.ifes.edu.br/handle/123456789/562>

BOGDAN, R.; BIKLEN, S. Investigação Qualitativa em Educação - uma introdução à teoria e aos métodos. Portugal: Porto Editora, 1994.

BRASIL. Ministério da Educação, Secretaria de Educação Básica, Secretaria de Educação Continuada, Alfabetização, Diversidade e Inclusão. Conselho Nacional de Educação. Diretrizes Curriculares Nacionais Gerais da Educação Básica/ Ministério da Educação. Secretária de Educação Básica. Diretoria de Currículos e Educação Integral. - Brasília: MEC/SEB, 2013. Disponível em: $<$ http://portal.mec.gov.br/index.php?option=com docman\&view=download\&alias $=$ 15548-d-c-n-educacao-basica-nova-pdf\&Itemid=30192>

BRASIL. Lei 10.639 de 9 de janeiro de 2003. Disponível em: <http://www.planalto.gov.br/ccivil 03/leis/2003/l10.639.htm>.

BRASIL. Lei 11.648 de 20 de dezembro de 2008 . Disponível em:< http://www.planalto.gov.br/ccivil 03/ Ato2007-2010/2008/Lei/L11645.htm>

BRASIL. Ministério da Cultura, Fundação Palmares. Conferência Mundial contra o Racismo, Discriminação Racial, Xenofobia e Intolerância Correlata. 2001. Disponível em <https://nacoesunidas.org/wp-content/uploads/2015/03/durban2001.pdf >

BRASIL. Ministério da Educação, Secretaria da Educação Continuada, Alfabetização e Diversidade. Orientações e Ações para Educação das Relações ÉtnicoRaciais. Brasília: SECAD, 2006. Disponível em: <http://portal.mec.gov.br/dmdocuments/orientacoes etnicoraciais.pdf>

FORDE, G. H. A.; VENERANO, Izaura Márcia; NEVES, Yasmim Poltronieri. A educação anti-racista. Núcleo de currículo - CEAFRO - SEME/PMV, 2004. 
em:

FORDE, G. H. A. Vozes negras na história da educação: Racismo, educação e movimento negro no Espírito Santo (1978-2002). Campo dos Goytacazes, RJ: Brasil Multicultural,2018.

FORDE, G. H. A. A presença africana no ensino de matemática: análises dialogadas entre história, etnocentrismo e educação. $276 \mathrm{f}$. Dissertação (Mestrado em Educação) - Universidade Federal do Espírito Santo, Vitória, 2008. . Disponível em:

http://portais4.ufes.br/posgrad/teses/nometese_124_GUSTAVO\%20HENRIQUE\% 20ARA\%DAJO\%20FORDE.pdf >

PETIT, S. H. Práticas Pedagógicas para a Lei $\mathbf{N}^{\circ}$ 10.639/ 2003: A criação de nova abordagem de formação na perspectiva das africanidades. Educ. Foco, Juiz de Fora, v.21, n.3, 657- 684,set. / dez. 2016. Disponível em: < https://periodicos.ufff.br/index.php/edufoco/article/view/19874>.

GIL, A. Métodos e Técnicas de Pesquisa Social. 6. ed., 3 reimpr., São Paulo: Atlas. 2010.

GOMES, J. B. B. Ação afirmativa e princípio constitucional da igualdade: o direito como instrumento de transformação social. Rio de Janeiro: Renovar, 2001.

GOMES, N.L. O Movimento Negro Educador: saberes construídos nas lutas por emancipação. Petrópolis, RJ: Vozes, 2017. $3^{\text {a }}$ reimpressão, 2018.

MUNANGA, K. Negritude: usos e sentidos. Belo Horizonte: Autêntica Editora, 2009.

SERRA, Prefeitura Municipal. Lei no 2387 de 30 de maio de 2oo1. Disponível em: $<$

http://prefeiturasempapel.serra.es.gov.br/Arquivo/Documents/legislacao/html/L23 872001.html>.

SERRA, Prefeitura Municipal. Orientação Curricular: De Educação Infantil e Ensino Fundamental: articulando saberes, tecendo diálogos. Secretaria Municipal de Educação / Departamento de Ensino. Serra: ABBA Gráfica e Editora, 2008. $300 \quad$ p. $\quad$ Disponível em: $<$ http://www4.serra.es.gov.br/site/download/1540303457867-orientao-curricular2008.pdf>

SILVA, D. V. C. A educação das relações étnico-raciais no ensino de Ciências : diálogos possíveis entre Brasil e Estados Unidos. Tese (Doutorado) -- 
Universidade Federal de São Carlos, 2009. Disponível em: < https://repositorio.ufscar.br/handle/ufscar/2222?show=full>

TRANCOSO, J. S. R. O Jogo uso do Jogo Awalé como possibilidade na educação matemática para EJA. 2019. 198 f. Dissertação (Mestrado em Educação Ciências e Matemática - EDUCIMAT) - Instituto Federal do Espírito

Santo, Vitória, $2019 . \quad$ Disponível em:< https://sucupira.capes.gov.br/sucupira/public/consultas/coleta/trabalhoConclusao/ viewTrabalhoConclusao.jsf?popup=true\&id trabalho=8544413 >

\section{Sobre os autores:}

Franciele Teixeira da Silva Polez: Graduada em Pedagogia pela Universidade Federal do Espírito Santo - UFES. Mestranda em Educação em Ciências e Matemática pelo Instituto Federal do Espírito Santo - IFES. Professora estatutária no município da Serra/ES desde 2016, onde atualmente é assessora pedagógica da pasta Étnico-racial na Secretaria Municipal de Educação -Sedu/Serra. Tem interesse pelas temáticas relacionadas a Educação das Relações Étnico-raciais- ERER e Gênero. E-mail: polezfranciele@gmail.com

Joelma dos Santos Rocha Trancoso: Graduada em Pedagogia pela Universidade Federal do Espírito Santo - UFES. Mestra em Educação em Ciências e Matemática pelo Instituto Federal do Espírito Santo - IFES. Professora estatutária no município da Serra/ES desde 2013, onde atualmente é gestora da pasta Étnico-racial na Secretaria Municipal de Educação -Sedu/Serra. Tem interesse pelas temáticas relacionadas a Educação das Relações Étnico-raciais- ERER, a Educação de Jovens e Adultos-EJA e a Educação Matemática. E-mail: jhoelmasrocha@gmail.com

Eduardo Augusto Moscon Oliveira: Graduado em História pela UFES, Mestre em Educação Pela UFES, Doutor em Educação pela UFBA, Professor do Departamento de Educação Política e Sociedade do Centro de Educação da UFES. Professor do Programa de Pós-Graduação Mestrado Profissional da UFES - PPGMPE. Professor colaborador do Programa de Pós-Graduação em educação em Ciências de Matemática do IFESEDUCIMAT. E-mail: eduardo.moscon@ufes.br 